\title{
Preliminary Analysis of Saudi National Seismic Network Recordings of the November 1999 Dead Sea Explosions
}

\author{
A. Rodgers \\ December 1, 1999
}

U.S. Department of Energy

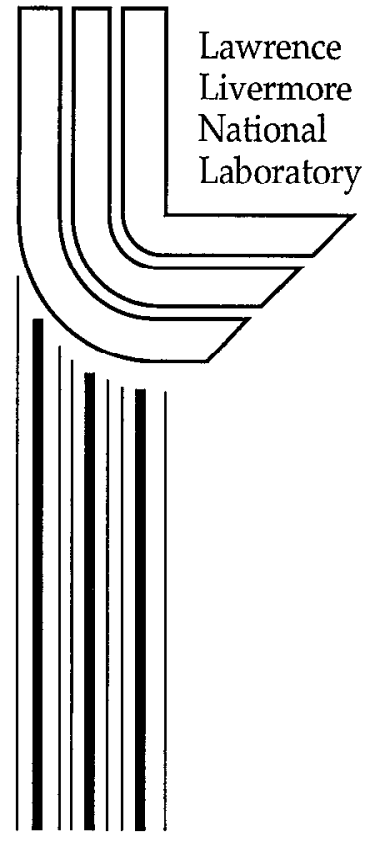




\section{DISCLAIMER}

This document was prepared as an account of work sponsored by an agency of the United States Government. Neither the United States Government nor the University of California nor any of their cmployecs, makes any warranty, express or implied, or assumes any legal liability or responsibility for the accuracy, completeness, or usefulness of any information, apparatus, product, or process disclosed, or represents that its usc would not infringe privately owned rights. Reference herein to any specific commercial product, process, or service by trade name, trademark, manufacturer, or otherwise, does not necessarily constitute or imply its endorsement, recommendation, or favoring by the United States Government or the University of California. The views and opinions of authors expressed herein do not necessarily state or reflect those of the United States Government or the University of California, and shall not be used for advertising or product endorsement purposes.

Work performed under the auspices of the U.S. Department of Energy by the University of California Lawrence Livermore National Laboratory under Contract W-7405-Eng-48.

This report has been reproduced directly from the best available copy.

Available to DOE and DOE contractors from the

Office of Scientific and Technical Information

P.O. Box 62, Oak Ridge, TN 37831

Prices available from (423) 576-8401

http://apollo.osti.gov/bridge/

Available to the public from the National Technical Information Service

U.S. Department of Commerce. 5285 Port Royal Rd., Springfield, VA 22161 http://www.ntis.gov/

\section{OR}

Lawrence Livermore National Laboratory Technical Information Department's Digital Library http://www.llnl.gov/tid/Library.html 


\title{
Preliminary Analysis of Saudi National Seismic Network Recordings of the November 1999 Dead Sea Explosions
}

\author{
Arthur Rodgers \\ Geophysics and Global Security Division \\ Earth and Environmental Sciences Directorate \\ Lawrence Livermore National Laboratory \\ Livermore, CA 94551 USA
}

\begin{abstract}
Two large chemical explosions were detonated in the Dead Sea on November 10 and 11, 1999 for the purposes of calibrating seismic travel times to improve regional network location. These explosions were large enough to be observed with good signal-to-noise ratios by seismic stations in northwestern Saudi Arabia (distances $<500 \mathrm{~km}$ ). In this report, we present a preliminary analysis of the recordings from these shots.
\end{abstract}




\section{Introduction}

The Dead Sea explosions were recorded by stations of the Saudi National Seismic Network (SNSN) in northeastern Saudi Arabia. The SNSN stations consist primarily of broadband (Streckeisen STS-2) and short-pcriod (Ranger 1-Hz) instrumentation and record at a sampling rate of $100 / \mathrm{sec}$. Figure 1 shows the explosion and station locations. The shot location (star) was taken from the Geophysical Institute of Israel (GII http://www.gii.co.il) announcement. The paths range in distance from $180-480 \mathrm{~km}$. At further ranges the signal-to-noise ratio is low. The recorded shot on November 10 had a local magnitude of 3.6 reported by GII. No magnitude information was available for the November 11 shot, but it was recorded with amplitudes roughly a factor of 2 larger than the November 10 shot.

Figures 2 and 3 show the waveforms recorded for the November 10 and 11 shots, respectively. The data were demeaned, tapered and high-pass filtered with a corner frequency of $1 \mathrm{~Hz}$. Inspection of the broadband records revealed no long-period energy (frequencies $<0.2 \mathrm{~Hz}$ ). Travel times of the main regional phases $(\mathrm{Pn}, \mathrm{Pg}$ and $\mathrm{Sg}$ ) were picked from the filtered data. The horizontal components of station DBAS were not working properly at the time of the shots.

Notice the impulsive first arriving P-wave observed at QURS. This is probably the crustal P-wave, Pg. This phase is seen on the more distant records. At station ALWS the first arriving P-wave is probably $\mathrm{Pn}$ and is followed by Pg. At further stations the Pn and 
$\mathrm{Pg}$ arrivals become more separated in time. The crustal S-wave, $\mathrm{Sg}$, is best observed on the horizontal components but is still difficult to pick with high accuracy. The mantle Swave, $\mathrm{Sn}$, was difficult to observe on all traces and was not picked.

\section{Travel Times}

Figure 4 shows the travel times versus distance from which apparent velocities may be inferred. The arrivals from both shots are plotted. The travel times were calculated using the announced location and origin time (Table 2). Apparent velocities are shown assuming an intercept time for $\mathrm{P}$ - and $\mathrm{S}$-waves of 5 and 10 seconds, respectively. Notice that the $\mathrm{Pn}, \mathrm{Pg}$ and $\mathrm{Sg}$ phases arrive with apparent velocities of 8.0, 6.5 and $3.8 \mathrm{~km} / \mathrm{s}$, respectively. These travel times may be used to develop a velocity model for regional network location for the Gulf of Aqaba region.

\section{SNSN Event Locations}

Figure 1 also shows the automatic locations from the SNSN real-time system. These locations are based on automatically detected P-waves and the iasp91 velocity model. While not in agreement with the ground truth, the automatic locations are reasonably good. The mislocation from the reported ground truth is given in Table 1. The location can be improved by using human analyst travel picks and a better velocity model. 


\section{Conclusions}

The Saudi National Seismic Network recorded the Dead Sea shots with good signal-to-noise out to ranges of almost $500 \mathrm{~km}$. These recordings provide an excellent data source for the development of a regional velocity model. Future research will focus on velocity model development and magnitude calibration.

\section{Acknowledgements}

This analysis was performed while the author was visiting the Institute for Astronomy and Geophysics Research (IAGR) at King Abdulaziz City for Science and Technology (KACST) in Riyadh, Kingdom of Saudi Arabia. The IAGR operates the Saudi National Seismic Network under the direction of Dr. Abdullah Ar-Rajehi. The author wishes to thank Dr. Ar-Rajehi and his staff for their gracious hospitality during his visit to KACST. This work was performed in part under the auspices of the U.S. Department of Energy by the Lawrence Livermore National Laboratory under contract W-7405-ENG-48. This is LLNL contribution UCRL-ID-??????.

Table 1. Automatic Locations of Dead Sea Shots by Saudi National Seismic Network.

Latitude Longitude Date Time (GMT) Mislocation $(\mathrm{km})$

$\begin{array}{lllll}31.6214 & 35.1506 & \text { Nov. } 10,1999 & 13: 59: 58.807 & 29.108\end{array}$

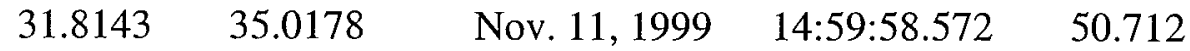

Table 2. Ground Truth Location from Geophysical Institute of Israel

Latitude Longitude Date Time (GMT) Yield (kg TNT) 


$\begin{array}{lllll}31.5338 & 35.4400 & \text { Nov. 10, 1999 } & 13: 59: 52.200 & 2060 \\ 31.5336 & 35.4413 & \text { Nov. 11, 1999 } & 15: 00: 00.785 & 5000\end{array}$




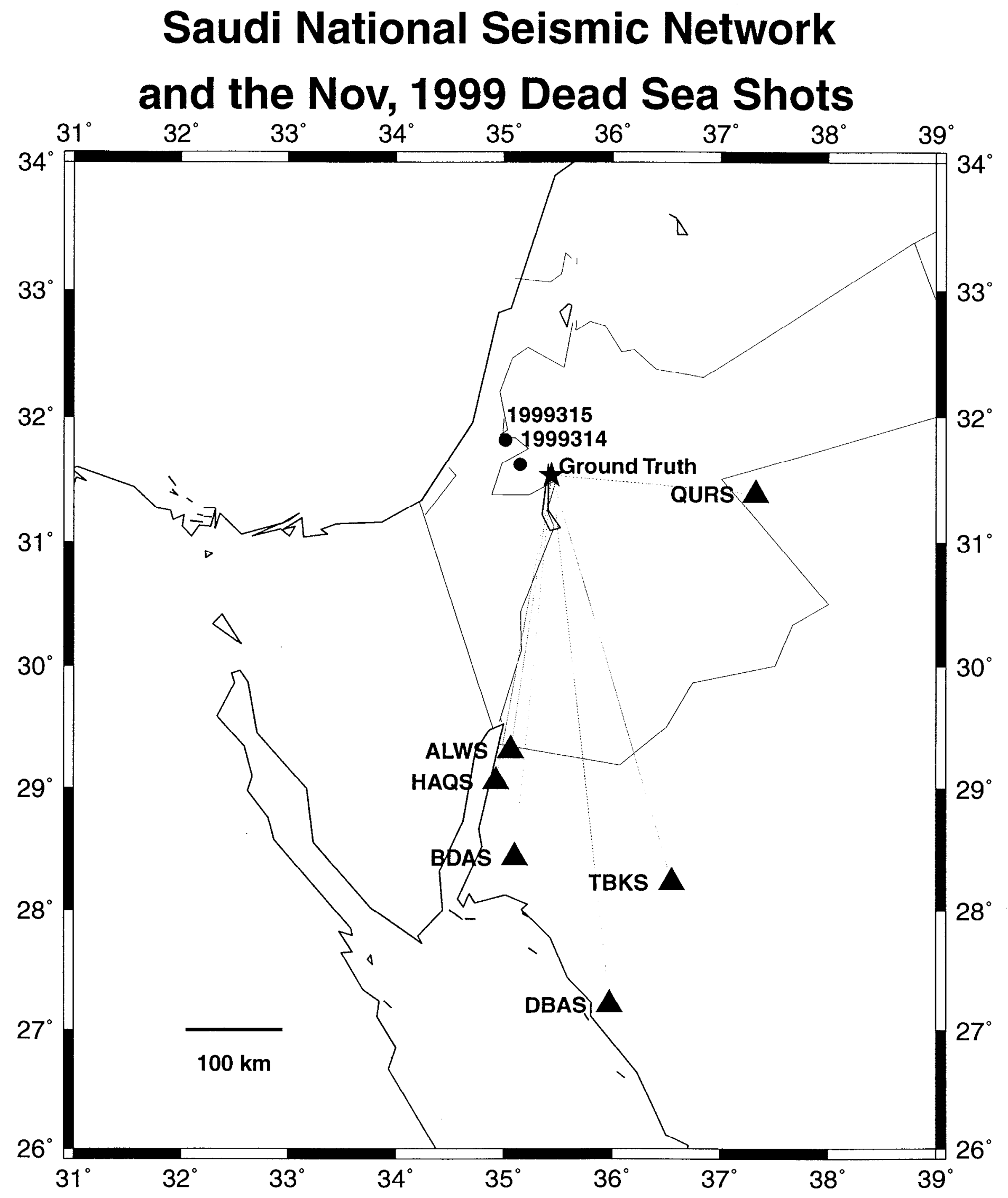

Figure 1. Map showing the locations of the Dead Sea shots and the SNSN stations that recorded the shots. 
Saudi National Seismic Network Recordings of the Nov 10, 1999 Dead Sea Shot
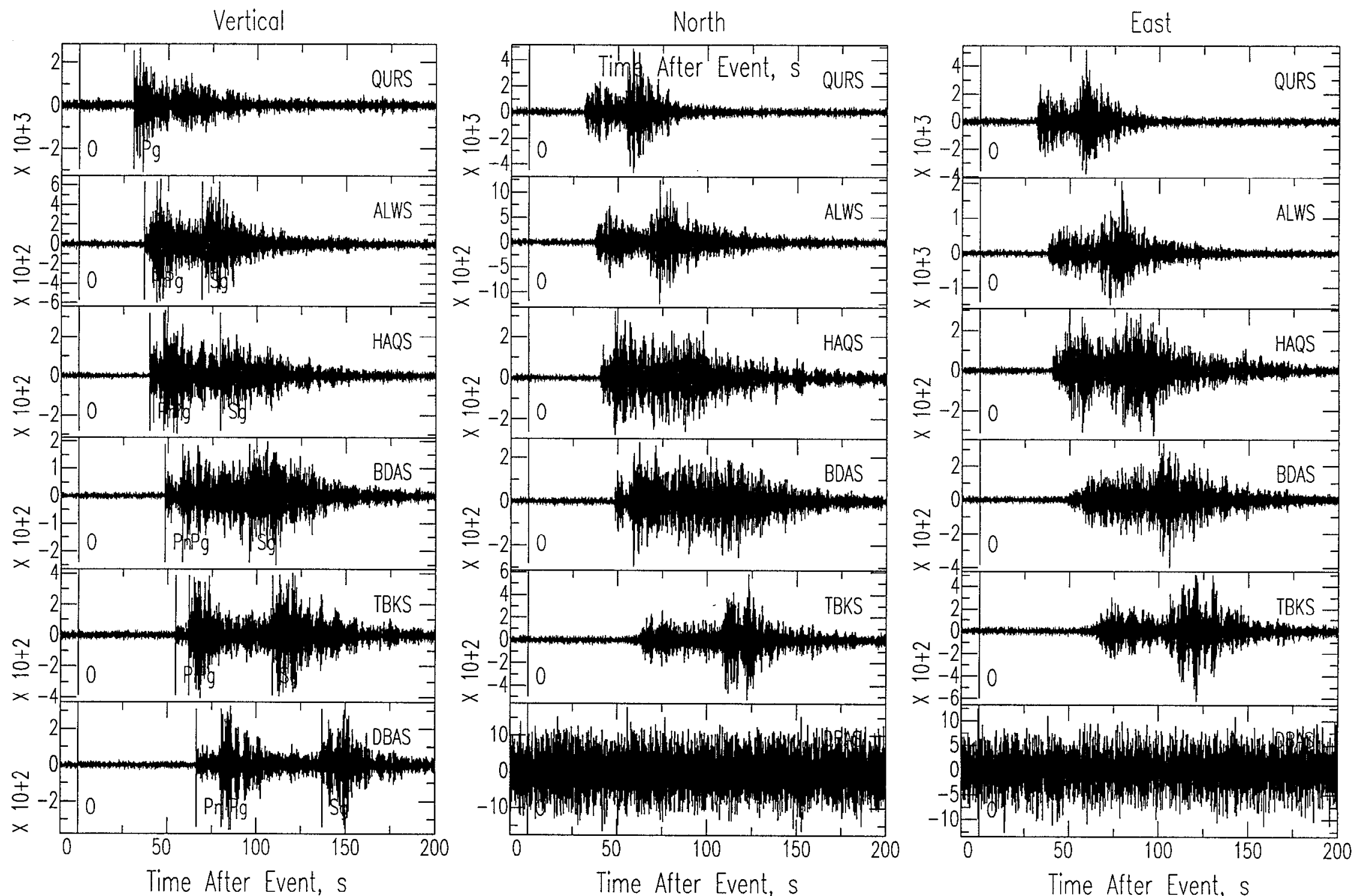

Figure 2. Waveforms for the November 10, 1999 shot, high-pass filtered with a corner frequency of $1 \mathrm{~Hz}$.

Note that all traces are plotted on a different scale. 
Saudi National Seismic Network Recordings of the Nov 11, 1999 Dead Sea Shot
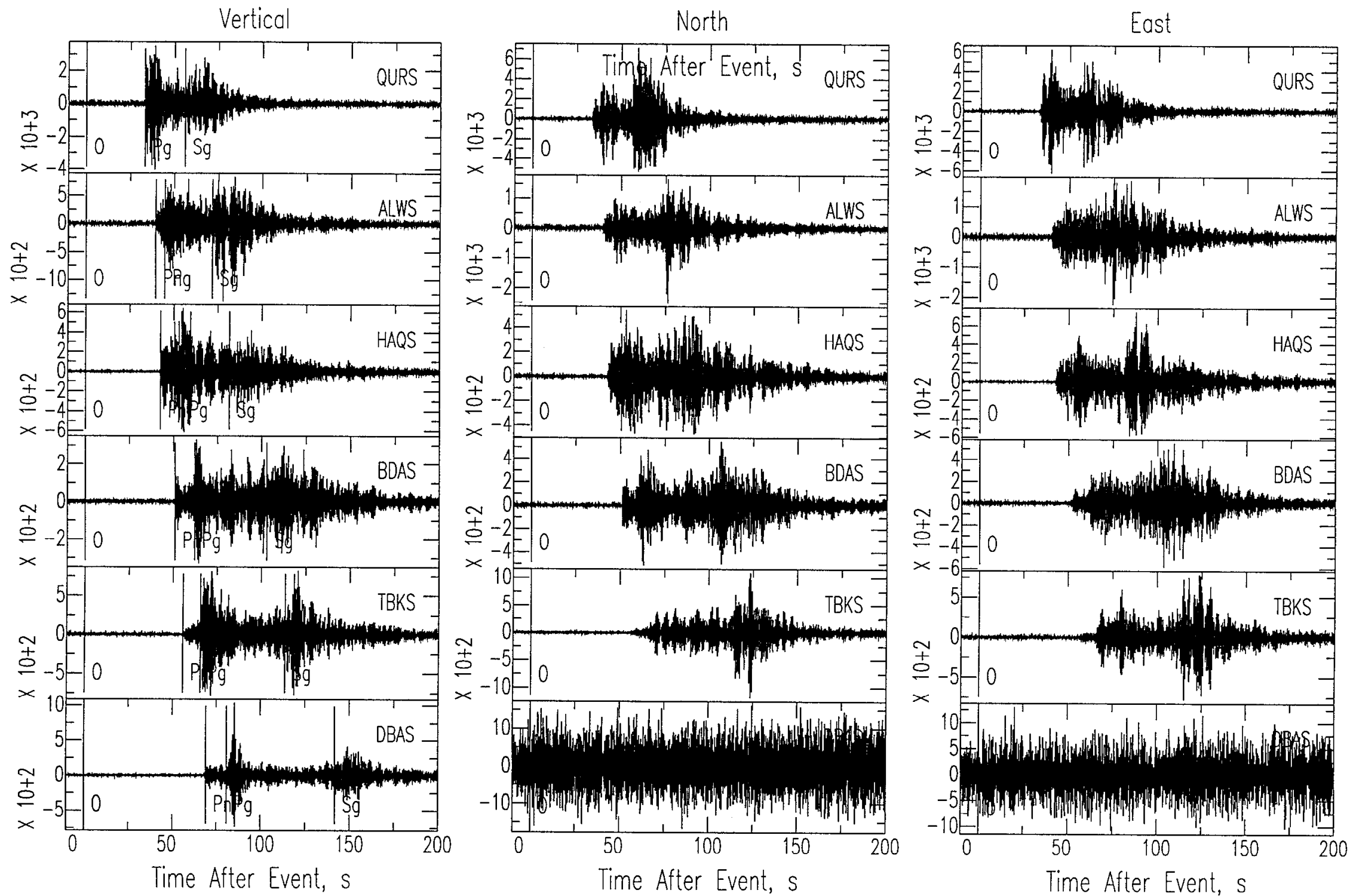

Figure 3. Waveforms for the November 11, 1999 shot, high-pass filtered with a corner frequency of $1 \mathrm{~Hz}$.

Note that all traces are plotted on a different scale. 


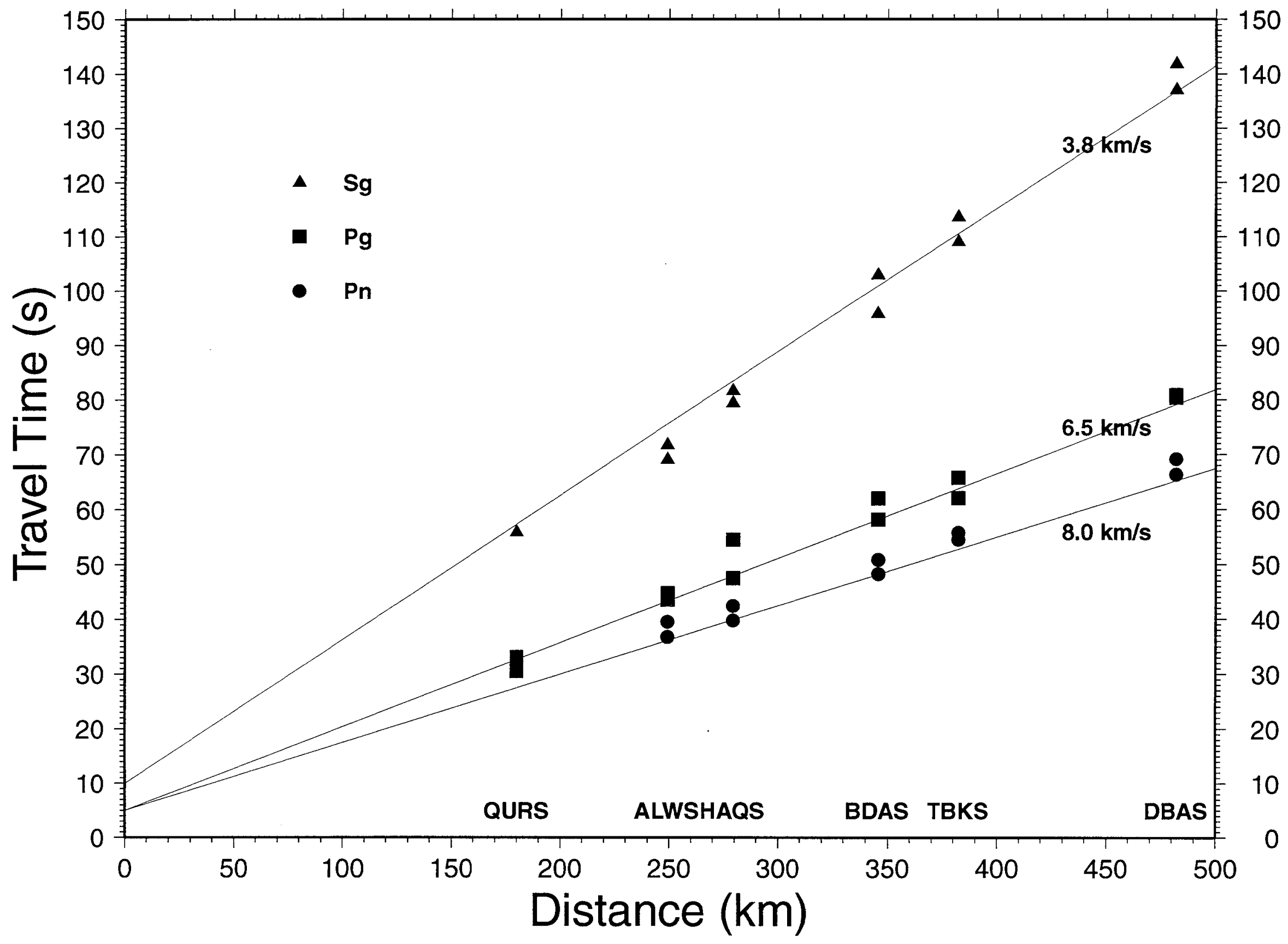

Figure 4. Travel times for regional phases $\mathrm{Pn}, \mathrm{Pg}$ and $\mathrm{Sg}$ plotted as a function of distance. 